\title{
A Rare Case of Gastric Perforation Secondary to Endoscopic Glue Injection for Gastric Varices
}

\author{
Varun Khandagale $^{1}$ Sandesh Sharma ${ }^{1}$ Pranav Raghuwanshi $^{1}$ Sanjay Kumar ${ }^{1}$ \\ ${ }^{1}$ Gastrocare Liver and Digestive Disease Centre, Bhopal, Madhya \\ Pradesh, India

\begin{abstract}
Address for correspondence Sanjay Kumar, DM (Gastroenterology), Gastrocare Liver and Digestive Disease Centre, Bhopal, Madhya Pradesh, India (e-mail: sanjaykr.gastro@gmail.com).
\end{abstract}

J Digest Endosc 2022;13:55-57.

\begin{abstract}
Keywords

- perforation

- gastric varices

- glue injection

Gastric perforation is very rare. Gastric perforation following endoscopic glue injection for gastric varices (GVs) in patients with portal hypertension (PHT) has not been documented till date. They are associated with significant morbidity and mortality. We present a glue injection-induced gastric perforation in patients with PHT that has been treated with primary closure at our institution. To the best of our knowledge, this is the first case report of such complication following endoscopic glue injection for GVs. Such site of glue-induced perforation has not been reported in literature till date. A 38-yearold male patient having cirrhosis of liver with PHT underwent repeated upper gastrointestinal (GI) endoscopic procedures for recurrent upper $\mathrm{Gl}$ bleed. After 20 days of third endoscopic procedure in which he had undergone glue injection for GVs, patient developed abdominal pain and abdominal radiograph was suggestive of bowel perforation. Emergency laparotomy was performed that showed gastric perforation near to glue injection site which was repaired with primary closure at our institution. Complication such as glue injection-induced gastric perforation has not yet been documented. It is potentially life-threatening. Early recognition may lead to a better prognosis through earlier intervention.
\end{abstract}

\section{Introduction}

The natural history of gastric varices (GVs) is quite less understood than that of esophageal varices (EVs). GVs may be seen in 18 to $70 \%$ of the patients with portal hypertension (PHT) and are a probable source of bleeding in 10 to $36 \%$ of patients with acute variceal bleeding. ${ }^{1-4}$ The risk of bleeding from GVs seems to be lower than that of EVs; however, when GVs bleed, it is often severe and bleeding-related mortality can be as high as $45 \%$. Endoscopic treatment of bleeding GVs with $\mathrm{N}$-butyl-2-cyanoacrylate glue (cyanoacrylate) is considered the best hemostasis with a lower risk of rebleeding compared with other endoscopic methods. The reported rate of rebleed- ing varies significantly from 0 to $50 \%$ in studies. ${ }^{5,6}$ There is also a potential risk of embolism especially in patients with underlying gastrorenal or gastrocaval shunts. Other serious complications reported in literature are sepsis, fistula, and adherence of the needle to the varix. ${ }^{7,8}$ We present a case with glue injection-induced gastric perforation, which was successfully managed by primary closure of perforation.

\section{Case Report}

A 38-year-old male, who was recently diagnosed with ethanol-induced cirrhosis of the liver with PHT (Child C MELD
DOI https://doi.org/ 10.1055/s-0040-1721225. ISSN 0976-5042. (c) 2022. Society of Gastrointestinal Endoscopy of India. All rights reserved.

This is an open access article published by Thieme under the terms of the Creative Commons Attribution-NonDerivative-NonCommercial-License, permitting copying and reproduction so long as the original work is given appropriate credit. Contents may not be used for commercial purposes, or adapted, remixed, transformed or built upon. (https://creativecommons.org/ licenses/by-nc-nd/4.0/)

Thieme Medical and Scientific Publishers Pvt. Ltd., A-12, 2nd Floor, Sector 2, Noida-201301 UP, India 
24), was first admitted to our hospital in intensive care unit (ICU) with grade III hepatic encephalopathy (HE) and ascites. He had a history of hematemesis 2 days before admission. Gastroscopy showed large EVs with red-color signs and severe portal hypertensive gastropathy (PHG). He underwent endoscopic variceal band ligation (EVL) procedure. Other issues such as grade III HE, coagulopathy, and spontaneous bacterial peritonitis were managed accordingly. The patient was discharged in stable condition.

Patient presented again $\sim 20$ days later with hematemesis. Upper gastrointestinal endoscopy showed residual varices with post-EVL ulcers, small gastroesophageal varix type 1 (GOV1) with stigmata of bleeding. About $1 \mathrm{~mL}$ of undiluted cyanoacrylate glue was injected into GV using a $21 \mathrm{G}$ sclerotherapy needle (-Fig. 1A and B). On observing for few minutes as there was mild ooze, additional $0.5 \mathrm{~mL}$ glue was injected using a separate $21 \mathrm{G}$ sclerotherapy needle. He was discharged in stable condition.

About 20 days following this discharge, he presented with complaints of severe abdominal. The pain was diffuse over abdomen, moderate intensity, nonradiating pain which was not associated with vomiting. He also complained of abdominal distension for past 3 days along with decreased urine output. On examination, the patient had tachypnea, tachycardia, hypotension, deep icterus, and bilateral pedal edema. Abdomen was distended with diffuse tenderness and sluggish bowel sounds. The patient was admitted to ICU. Labs showed severe anemia, thrombocytopenia, coagulopathy, and acute kidney injury. Ultrasonography-guided diagnostic ascitic tapping showed hemorrhagic fluid with high white blood cell count $\left(30,000\right.$ cells per $\left.\mathrm{mm}^{3}\right)$. Abdominal radiograph was suggestive of pneumoperitoneum.

After stabilization of general condition, decision for emergency laparotomy was taken after explaining the potential risks. With the availability of fresh frozen plasma, platelet, and cryoprecipitate for transfusion during surgery, the patient was taken for emergency laparotomy.

Intraoperatively, we found blood in peritoneal cavity. The examination of bowel initially did not reveal any perforation; however, thorough examination showed perforation site near gastroesophageal junction (-Fig. 2). Site of perforation was sutured, and two drains were kept in peritoneal cavity: one in the left subdiaphragmatic space and other in pelvis.

In postoperative period, the patient was managed in ICU on vasopressors and adequate transfusion of platelets, fresh frozen plasma, cryoprecipitate along with other supportive medications. He had a difficult postoperative course but
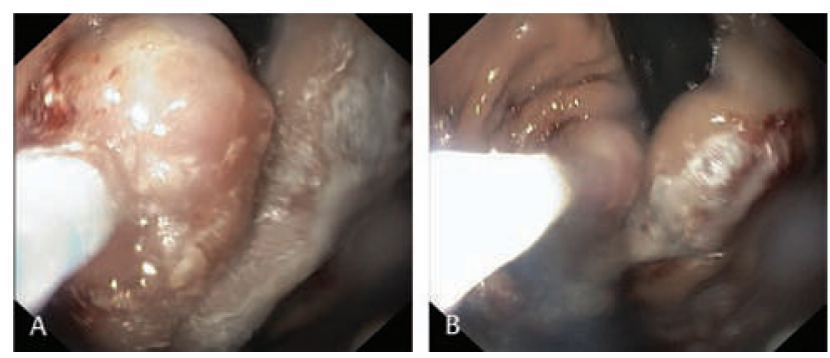

Fig. 1 Glue injection into gastric varix.

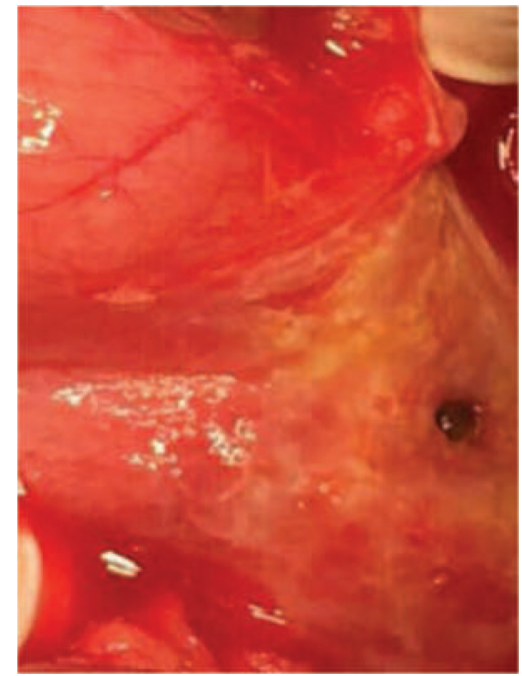

Fig. 2 Per-opearative picture of perforation.

finally discharged in stable condition after 10 days. Repeat gastroscopy after 1 month showed a glue cast but no active gastric varix.

\section{Discussion}

Although glue injection is one of the proven treatment modalities for GVs, glue-related perforation is a dreaded complication for both patient and the physician after an episode of bleeding from GOV.

Various complications which can occur after glue injection of GVs are embolization, local venous thrombosis, fistulization, ulceration, erosion, extrusion, and sepsis. ${ }^{7-9}$

Clinical presentation of gastric perforation in cirrhotic patient may be from mild abdominal tenderness to generalized peritonitis. It can be diagnosed on abdominal radiograph as in our case with finding of pneumoperitoneum or on computed tomography.

Cause for gastric perforation in our case can be extravascular injection of the glue into the gastric wall. On reviewing the videos of glue injection, it was apparent that the endoscopist injected from the top of varix, but he was too close to the varix; hence, it was not possible to see the depth. Therefore, probably the injection was too deep (-Fig. 1A and 1B). The presence of PHG and coagulopathy in this decompensated cirrhotic patient may have contributed further by formation of hematoma in the gastric wall that may have resulted in deep ulcer and perforation at the injection site. Literature search did not reveal cases of perforation after glue injection. Battaglia et al report two cases of visceral fistulae after Histoacryl injection, a previously unreported complication. One patient underwent treatment of GVs, which was complicated by an empyema of the left pleural cavity 6 months later. A fistulous connection between the gastric fundus and pleural cavity was documented. Authors suggested that misguided injection of Histoacryl into the stomach wall may have caused this 
complication, as Histoacryl is known to be ulcerogenic to tissue. $^{10}$

The management of gastric perforation in a patient with decompensated cirrhosis is a challenge considering various issues such as ascites, jaundice, hypoalbuminemia, coagulopathy, and sepsis. Moreover, surgical repair of gastric wall at perforation site in patient having PHG is tough job for an operating surgeon. Correction of coagulopathy and thrombocytopenia is required during intra- and postoperative period.

The prevention of occurrence of this kind of complication can be achieved by careful injection of glue into the vascular lumen after confirming needle position by aspirating blood, or by adopting image-guided glue injection technique (fluoroscopy-guided or endoscopic ultrasound-guided injection).

\section{Conclusion}

Glue-induced gastric perforation has not yet been documented. It is potentially life-threatening and difficult to manage in the presence of decompensated cirrhosis. Careful injection of the glue into the vascular lumen preventing extravascular extrusion into gastric wall can prevent this complication.

Funding

None.

Conflict of Interest

None declared.

\section{References}

1 Garcia-Tsao G, Sanyal AJ, Grace ND, Carey WPractice Guidelines Committee of the American Association for the Study of Liver Diseases Practice Parameters Committee of the American College of Gastroenterology. Prevention and management of gastroesophageal varices and variceal hemorrhage in cirrhosis. Hepatology 2007;46(03):922-938

2 Qureshi W, Adler DG, Davila Ret al.Standards of Practice Committee. ASGE Guideline: the role of endoscopy in the management of variceal hemorrhage, updated July 2005. Gastrointest Endosc 2005;62(05):651-655

3 de Franchis R, Baveno VBaveno V Faculty. Revising consensus in portal hypertension: report of the Baveno $\mathrm{V}$ consensus workshop on methodology of diagnosis and therapy in portal hypertension.J Hepatol 2010;53(04):762-768

4 Sarin SK, Lahoti D, Saxena SP, Murthy NS, Makwana UK. Prevalence, classification and natural history of gastric varices: a longterm follow-up study in 568 portal hypertension patients. Hepatology 1992;16(06):1343-1349

5 Akahoshi T, Hashizume M, Shimabukuro Ret al.Long-term results of endoscopic Histoacryl injection sclerotherapy for gastric variceal bleeding: a 10-year experience. Surgery 2002;131(Suppl 1): S176-S181

6 Evrard S, Dumonceau JM, Delhaye M, Golstein P, DeviÃ̈re J, Le Moine O. Endoscopic Histoacryl obliteration vs. propranolol in the prevention of esophagogastric variceal rebleeding: a randomized trial. Endoscopy 2003;35(09):729-735

7 Seewald S, Ang TL, Imazu Het al.A standardized injection technique and regimen ensures success and safety of N-butyl-2cyanoacrylate injection for the treatment of gastric fundal varices (with videos);. Gastrointest Endosc 2008;68(03):447-454

8 Cheng LF, Wang ZQ, Li CZ, Lin W, Yeo AE, Jin B. Low incidence of complications from endoscopic gastric variceal obturation with butyl cyanoacrylate. Clin Gastroenterol Hepatol 2010;8(09): 760-766

9 Al-Hillawi L, Wong T, Tritto G, Berry PA. Pitfalls in Histoacryl glue injection therapy for oesophageal, gastric and ectopic varices: a review. World J Gastrointest Surg 2016;8(11):729-734

10 Battaglia G, Morbin T, Patarnello E, Ancona E, Merkel C, Corona M. Visceral fistulae as a complication of sclerotherapy for oesophageal and gastric varices using isobutyl-2-cyanoacrylate. Gastrointest Endosc 2000;52:267-270 